\title{
TO THE 100TH ANNIVERSARY OF MIKHAIL M. ODINTSOV, CORRESPONDING MEMBER OF THE USSR ACADEMY OF SCIENCES
}

\author{
D. P. Gladkochub, R. P. Dorofeeva, K. N. Egorov \\ Institute of the Earth's Crust, Siberian Branch of RAS, 664033, Irkutsk, Lermontov street, 128, Russia
}

\begin{abstract}
This article provides basic information about Mikhail M. Odintsov (1911-2011), Corresponding Member of the USSR Academy of Sciences, and his scientific, organizational and social activities. From 1954 to 1976, he was the founder and director of the Institute of Geology of the East Siberian Branch of the USSR Academy of Sciences, which is now world known as the Institute of Earth's Crust of the Siberian Branch of the Russian Academy of Sciences. The Institute was awarded with two Orders of Lenin (in 1963, and in 1971), and the Order of Red Banner of Labour (1975). In 2011, the scientific community in Russia celebrates the 100th anniversary of Mikhail M. Odintsov.
\end{abstract}

Key words: Siberian platform, prediction of mineral reserves, kimberlite pipes, diamonds.

Recommended by E.V. Sklyarov 10 October 2011

Citation: Gladkochub D.P., Dorofeeva R.P., Egorov K.N. To the 100th anniversary of Mikhail M. Odintsov, Corresponding Member of the USSR Academy of Sciences // Geodynamics \& Tectonophysics. 2011. V. 2. № 4. P. 425-429. doi:10.5800/GT-2011-2-4-0054.

\section{К 100-ЛЕТИЮ СО ДНЯ РОЖДЕНИЯ ЧЛЕНА-КОРРЕСПОНДЕНТА АН СССР МИХАИЛА МИХАЙЛОВИЧА ОДИНЦОВА}

\author{
Д. П. Гладкочуб, Р. П. Дорофеева, К. Н. Егоров \\ Институт земной коры СО РАН, 664033, Иркутск, ул. Лермонтова, 128, Россия
}

\begin{abstract}
Аннотация: В статье приведены основные сведения о научной, научно-организационной и общественной деятельности члена-корреспондента АН СССР М.М. Одинцова (1911-2011 гг.) - одного из основателей и руководителей (1954-1976 гг.) Института геологии Восточно-Сибирского филиала АН СССР - Института земной коры СО АН, награжденного орденами Ленина (1963 г., 1971 г.) и орденом Трудового Красного Знамени (1975 г.), столетие со дня рождения которого отечественная геологическая общественность отмечает в 2011 г.
\end{abstract}

Ключевые слова: Сибирская платформа, прогноз эндогенных полезных ископаемых, кимберлитовые трубки, алмазы. 


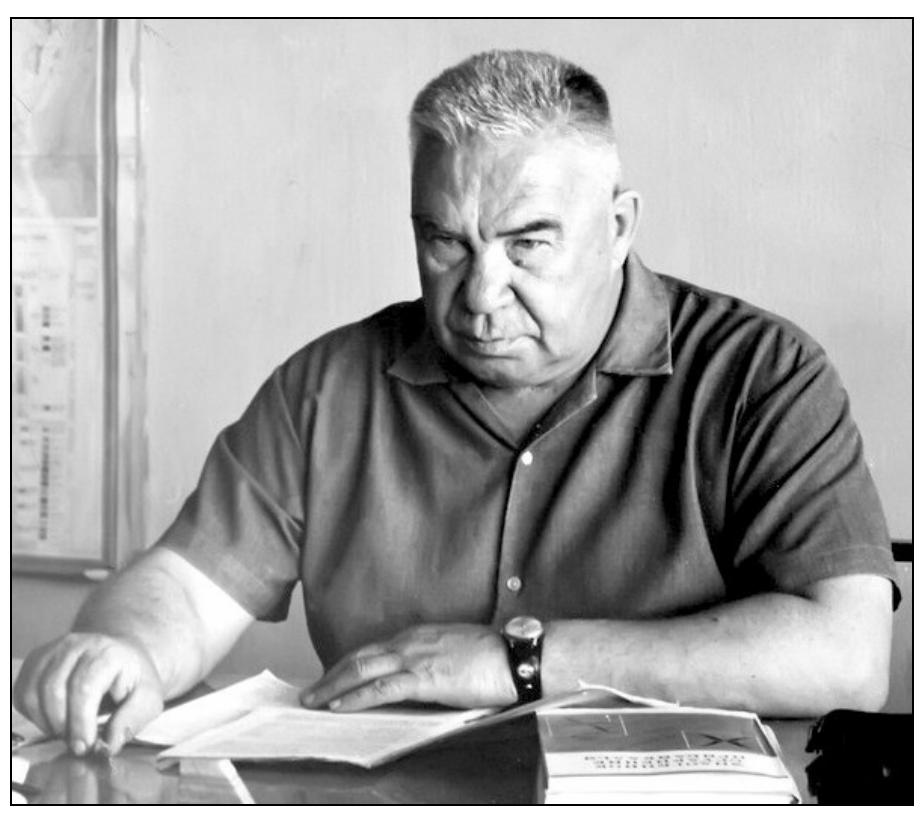

Рис. 1. Михаил Михайлович Одинцов - доктор геолого-минералогических наук, профессор, член-корреспондент АН СССР.

Fig. 1. Mikhail M. Odintsov, Professor, Doctor of Geology and Mineralogy, Corresponding Member of the USSR Academy of Sciences.

В 2011 г., в год 350-летия г. Иркутска, исполнилось бы 100 лет члену-корреспонденту АН СССР Михаилу Михайловичу Одинцову - крупному ученому-геологу, признанному лидеру в исследовании тектоники, магматизма, минерагении древних платформ, в первую очередь Сибирской платформы. Значительным результатом его научной деятельности, получившим мировую известность, стал блестящий прогноз перспектив коренной и россыпной алмазоносности Сибирской платформы.

М.М. Одинцов родился 5 ноября 1911 г. в г. Иркутске. В 1928 г. он поступил на естественное отделение Иркутского педагогического института, однако в 1930 г. решительно сменил педагогическую специализацию на геологическую. Окончив курсы коллекторов, а в 1932 г. - прорабов-геологов, он начал самостоятельную производственную деятельность в АнгароИлимской экспедиции Восточно-Сибирского геологогидро-геодезического треста.

Без отрыва от производства в 1936 г. М.М. Одинцов экстерном закончил Иркутский государственный университет по геологической специальности. После окончания ИГУ он параллельно с производственной деятельностью занимался преподавательской работой (1937-1944 гг.) - был старшим преподавателем Иркутского педагогического, Иркутского горно-металлургического (ныне НИ ИрГТУ) институтов и Иркутского государственного университета. Будучи доцентом, затем с 1949 г. профессором ИГУ, М.М. Одинцов в тече- ние 10 лет заведовал кафедрой исторической геологии, а в 1949-1953 гг. был деканом геологического факультета.

В 1934-1935 гг. М.М. Одинцов провел свои первые научно-исследовательские работы в Тайшетском и Братском районах, результаты которых были опубликованы в его первой монографии «Геологический очерк Тайшет-Братского района Восточной Сибири» (1937 г.). Следует отметить, что в дальнейшем эти результаты были достаточно эффективно использованы в процессе прокладки головного участка трассы БАМ Тайшет-Лена. Неслучайно в 80-х годах М.М. Одинцов стал одним из инициаторов комплексных исследований сейсмических, гидрогеологических, инженерногеологических условий и оценки минеральных ресурсов региона строительства БАМ.

В целом следует отметить, что итогом экспедиционных и научно-исследовательских работ М.М. Одинцова в Тайшетском и Братском районах в 1930-е годы явилось заложение основ представлений о строении южной части Сибирской платформы. Он определил юго-западную границу Сибирской платформы как зону тектонического контакта со складчатыми системами и при этом впервые включил в состав платформы восточную часть Енисейского кряжа, особо подчеркнув тесное взаимодействие структурных планов подошвы метаморфизованных пород чехла краевых частей платформы и складчатого обрамления.

Напряженная работа в производственных организациях способствовала его научному росту: в 1940 г. он успешно защитил кандидатскую, а в 1949 г. - докторскую диссертацию.

В 1939 г., сопоставив известные факты по геоло гии и магматизму Сибирской платформы с аналогичными данными по Южно-Африканской платформе, М.M. Одинцов сделал заключение о сходстве строения этих древнейших мегаблоков земной коры и внес предложение в Восточно-Сибирское геологическое управление начать работы по поиску алмазов на Сибирской платформе. Однако Великая Отечественная война помешала организации и проведению алмазопоисковых работ, так как все силы геологов были брошены на изыскание полезных ископаемых, непосредственно нужных фронту. В военные годы М.М. Одинцов руководил поисками и разведкой стратегического сырья. Огромная работоспособность позволила ему сочетать преподавание в вузах с практической работой в качестве начальника партий и технического руководителя экспедиций Иркутского геологического управления, трестов «Сибгеолнеруд» и «Союзслюда», проводивших геологическую съемку, поиски и разведку слюдяных, корундовых, графитовых, каолиновых, железорудных и меднорудных месторождений на Сибирской платформе, в Забайкалье, на Байкало-Патомском нагорье, Алдане и в Приморье. Особенно много сил, энергии он отдал организации добычи мусковита в Мамско-Чуйской слюдяной провинции. 


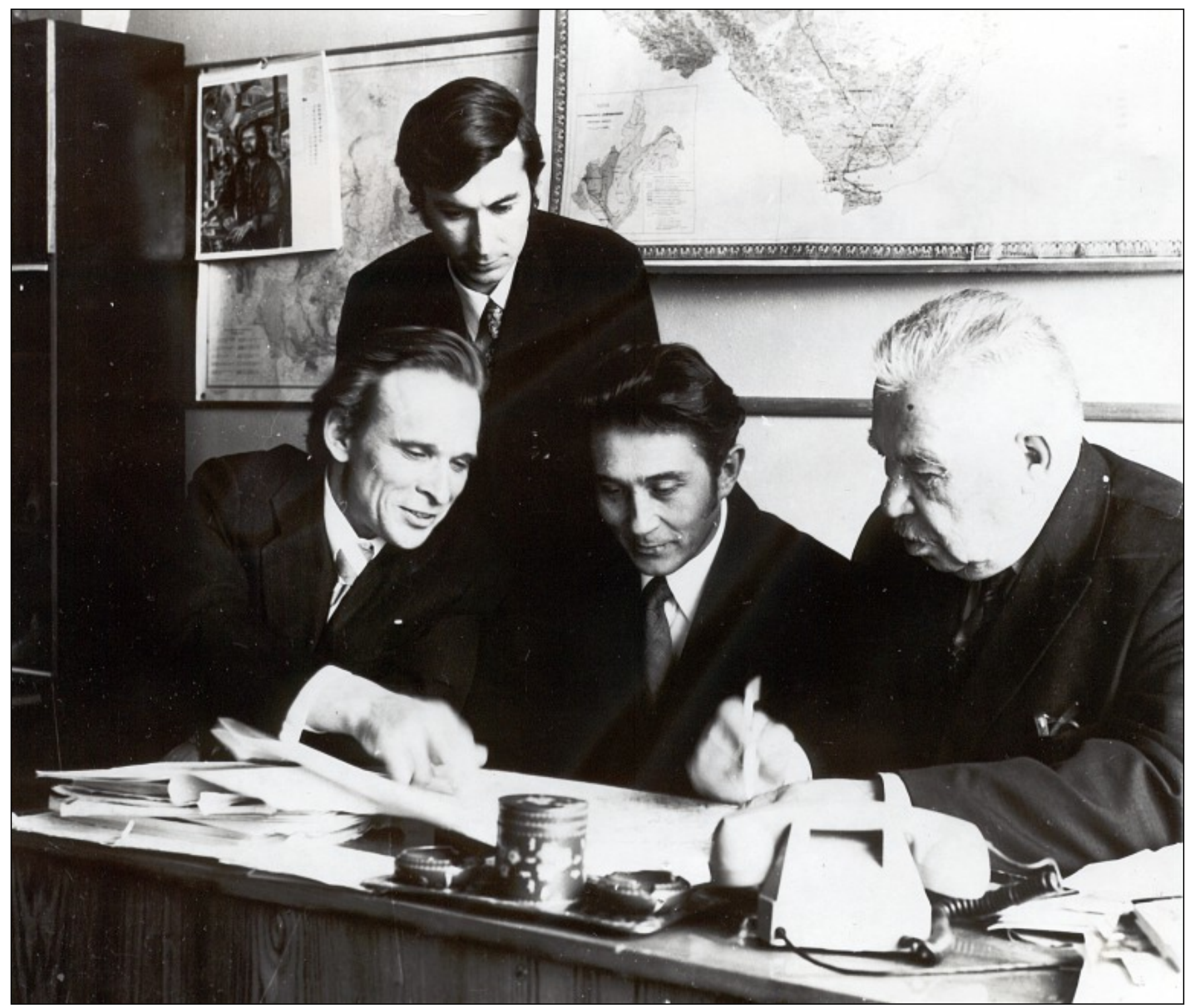

Рис. 2. М.М. Одинцов с сотрудниками лаборатории, 1974 г. Слева направо: П.П. Зуев, А.Г. Храмцов, В.Г. Домышев.

Fig. 2. Mikhail M. Odintsov and his colleagues in the laboratory (1974). Left to right: P.P. Zuev, A.G. Khamtsov, and V.G. Domyshev.

После окончания войны, в 1946 г., ВосточноСибирское геологическое управление поручило М.М. Одинцову составить проект поисков месторождений алмазов на Сибирской платформе. Была создана Тунгусская экспедиция в составе четырех партий, руководителями которых были геологи ВСГУ: В.В. Алексеев, В.Б. Белов, С.Н. Соколов и Г.Х. Файнштейн. Научное и техническое руководство экспедицией было возложено на профессора М.М. Одинцова, заведовавшего в то время кафедрой Иркутского госуниверситета. И уже в 1948 г. при обогащении террасовых отложений р. Малая Ерема (участок «Синий хребтик») был найден первый алмаз, с которого началась замечательная история открытия Якутской алмазоносной провинции. В 1949 г. единичные кристаллы алмаза были обнаружены на р. Большая Ерема (участок «Чайка») и в промышленных концентрациях в аллювиальных отложениях р. Вилюй. С этого времени М.М. Одинцов стал углубленно заниматься проблемой алмазоносности Сибирской платформы и заслужил в дальнейшем всеобщее признание как знаток геологии алмазных месторождений. И это справедливо, потому что М.М. Одинцов обосновал предположение, что есть на Сибирской платформе алмазы, первым поставил вопрос о начале их поисков, создал Тунгусскую, а впоследствии Амакинскую экспедицию, которая шесть лет работала под его руководством. Даже название экспедиции, ставшее известным на весь мир, придумал по имени своей любимой собаки Амака - по-эвенкийски медведь. 
С начала 1950-х годов М.М. Одинцов последовательно развивал представления о кимберлитовой природе сибирских алмазов и закономерностях пространственного размещения алмазных месторождений кимберлитов, а также создавал основные принципы минерагенического районирования древних платформ. Решающее значение в планировании дальнейших поисков коренных месторождений алмазов сыграли выводы М.M. Одинцова о кимберлитовой природе найденных алмазов, четкое определение вероятных эпох кимберлитового магматизма и разработка методики поисков кимберлитов.

Отсутствие в 40-х годах прошлого века достоверной геологической основы для прогнозируемых алмазоносных районов являлось значительным препятствием в ходе ведения поисковых работ на алмазы. В этой связи в 1949 г. М.М. Одинцов возглавил процесс планомерной геологической съемки громадных территорий в бассейнах рек Нижняя Тунгуска, Вилюй и Оленек. При этом были намечены и переданы Амакинской экспедиции наиболее перспективные участки для поисков алмазов, на которых последующие детальные изыскания привели к открытию ряда алмазоносных кимберлитовых трубок.

Позже М.M. Одинцов стал руководителем Северной экспедиции ИГУ, которая осуществляла геологическую съемку в масштабе 1:1000000 на алмазоносных площадях Сибирской платформы. В результате этих работ были созданы государственные геологические карты и карты полезных ископаемых, ставшие основой для планирования дальнейших поисков алмазов и других твердых полезных ископаемых. М.М. Одинцов не только руководил экспедициями, но и сам активно участвовал в полевых маршрутах, собирал фактический материал, который лег в основу его многочисленных публикаций.

В 1955 г. М.М. Одинцов наметил перспективы алмазоносности юго-западной части Сибирской платформы, а через два года организовал и возглавил совместные работы по этой проблеме Института земной коры и Иркутского геологического управления.

Много внимания М.М. Одинцов уделял изучению геологии, стратиграфии, тектоники и полезных ископаемых Восточной Сибири в целом. Его оригинальные идеи о мезозойском этапе развития структур востока Азиатского континента, о двух типах древних платформ и особенностях их развития способствуют прогнозированию месторождений золота и алмазов, меди и железа, редких элементов и других полезных ископаемых.

Особенности вулканизма и структурного развития платформ М.М. Одинцов считал специфической формой отражения общепланетарных закономерностей развития земной коры. Вышедшая уже после его смерти монография, посвященная Ангаро-Вилюйскому рудному поясу, освещает эту проблему на конкретном материале.
В начале 50-х гг. XIX века остро встал вопрос о реакции природной среды на создание каскада водохранилищ на р. Ангаре и промышленное освоение побережья оз. Байкал. М.М. Одинцов возглавил комплексные исследования Прибайкалья и районов водохранилищ, к которым привлек не только ИЗК АН СССР, но и другие научные учреждения Иркутского научного центра СО АН СССР.

В 1954 г. М.М. Одинцов возглавил Институт геологии Восточно-Сибирского филиала АН СССР. Под его руководством скромное научное учреждение из нескольких десятков научных и научно-технических сотрудников, ютившихся в старом здании, выросло в современный институт, занимающий одно из передовых мест в развитии геологических наук в Восточной Сибири. Само здание института строилось под постоянным контролем М.М. Одинцова, начиная от проекта до принятия сооружения в эксплуатацию.

М.М. Одинцов постоянно вел многостороннюю научно-организационную и общественно-политическую работу: в 1960-1965 гг. он был заместителем председателя, а в 1965-1969 гг. - председателем президиума Восточно-Сибирского филиала СО АН СССР. Он избирался депутатом Верховного Совета СССР (1958-1962 гг.), делегатом XXIII съезда КПСС, членом обкома, горкома, Свердловского райкома КПСС, депутатом областного и городского Советов народных депутатов, много лет возглавлял Иркутское отделение Общества советско-индийской дружбы. Значителен его вклад в развитие международного научного сотрудничества. М.М. Одинцов достойно представлял советскую науку на международных форумах. Он был участником сессий Международного геологического конгресса: XVII (г. Москва, 1937 г.), XXII (Индия, 1964 г.), XXIII (Прага, 1968 г.), членом Международной ассоциации по геологическому изучению глубинных зон земной коры и участвовал в сессиях этой ассоциации в Австрии (1965 г.), Канаде (1967 г.), СССР (1969 г.). Вел большую научно-организационную работу в составе Всесоюзного географического общества, Научного совета АН СССР по инженерной геологии и грунтоведению (Восточно-Сибирская секция), Научного совета АН СССР по проблемам БАМа, редколлегии журнала «Геология и геофизика».

М.М. Одинцов опубликовал около 200 научных работ, в том числе XVII том «Геологии СССР (Иркутская область)». Им подготовлено семь кандидатов и два доктора наук.

М.М. Одинцов был и остается образцом страстной целеустремленности, бескомпромиссности при решении важных проблем науки и общественной жизни. Ему была присуща доброжелательность к молодым специалистам, что наряду с высокой эрудицией в науке и общей культурой притягивало к нему молодежь. Сотни специалистов-геологов, работающих в научных и производственных организациях, - его ученики. M.M. Одинцов награжден двумя орденами Ленина, 
орденом Трудового Красного Знамени, многими медалями. Его многогранная деятельность - пример служения народу с отдачей всех сил, энциклопедических знаний и творческих возможностей.

В память о выдающемся первооткрывателе якутских алмазов чл.-корр. АН СССР М.М. Одинцове Со- вет Министров Якутской АССР принял решение назвать его именем крупный ювелирный алмаз (119.55 карата), добытый на обогатительной фабрике № 3 г. Мирного. Имя М.М. Одинцова присвоено крупной промышленно алмазоносной кимберлитовой трубке Далдыно-Алакитского района Якутии.

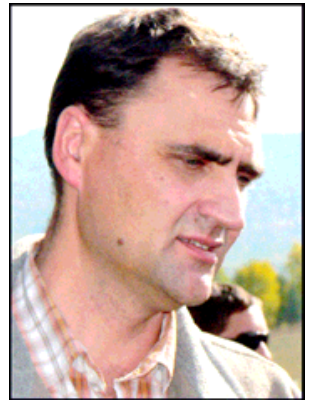

Гладкочуб Дмитрий Петрович, докт. геол.-мин. наук, и.о. директора института Институт земной коры СО РАН

664033, Иркутск, ул. Лермонтова, 128, Россия

\ e-mail: dima@crust.irk.ru

Gladkochub, Dmitry P., Doctor of Geology and Mineralogy, Deputy Director

Institute of the Earth's Crust, Siberian Branch of RAS

664033, Irkutsk, Lermontov street, 128, Russia

$\bowtie$ e-mail: dima@crust.irk.ru

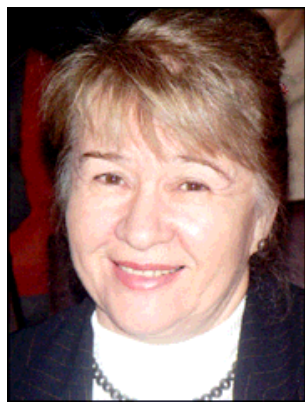

Дорофеева Раиса Петровна, канд. геол.-мин. наук, ученый секретарь

Институт земной коры СО РАН

664033, Иркутск, ул. Лермонтова, 128, Россия

Тел.: (3952)426900; e-mail: drf@crust.irk.ru

Dorofeeva, Raisa P., Candidate of Geology and Mineralogy, Secretary for Scientific Affairs Institute of the Earth's Crust, Siberian Branch of RAS

664033, Irkutsk, Lermontov street, 128, Russia

Tel.: (3952)426900; e-mail: drf@crust.irk.ru

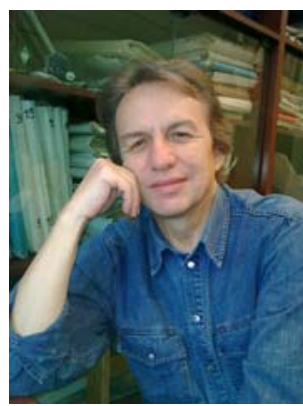

Егоров Константин Николаевич, канд. геол.-мин. наук, зав. лабораторией геологии и магматизма древних платформ Институт земной коры СО РАН

664033, Иркутск, ул. Лермонтова, 128, Россия

Тел.: (3952)425434 (служебный), (3952)563094 (домашний)

Egorov, Konstantin N., Candidate of Geology and Mineralogy,

Head of Ancient Platforms Geology \& Magmatism Laboratory, Siberian Branch of RAS

Institute of the Earth's Crust, Siberian Branch of RAS

664033, Irkutsk, Lermontov street, 128, Russia

Tel.: (3952)425434 (office), (3952)563094 (home) 